\title{
Um olhar sobre o cenário gastronômico de Brasília
}

\author{
Una mirada sobre el escenario gastronómico de Brasília \\ A look at the gastronomic scenario of Brasília
}

\section{Cláudia Nasser Brumano ${ }^{1}$}

Tainá Bacelar Zaneti ${ }^{2}$

\begin{abstract}
Resumo: O presente artigo tem como objetivo delinear o cenário gastronômico da cidade de Brasília a partir da narrativa de um dos pioneiros do mercado da gastronomia local, Francisco Ansiliero. Este é proprietário da rede Dom Francisco, cujo empreendimento no ramo alimentar é referência e faz parte do roteiro gastronômico local e nacional. Por meio de seu relato e apoiado em outras literaturas foi possível chegar a algumas considerações sobre a atual cena da gastronomia brasiliense, que por sua multiplicidade de influências, possui um "sabor todo especial".
\end{abstract}

Palavras-chave: Memória; cultura; identidade; gastronomia; Brasília.

Resumen: El presente artículo tiene como objetivo delinear el escenario gastronómico de la ciudad de Brasilia a partir de la narrativa de uno de los pioneros del mercado de la gastronomía local, Francisco Ansiliero. Este es propietario de la red Don Francisco, cuyo emprendimiento en la rama alimentaria es referencia y forma parte del itinerario gastronómico local y nacional. Por medio de su relato y apoyado en otras literaturas fue posible llegar a algunas consideraciones sobre la actual escena de la gastronomía brasiliense, que por su multiplicidad de influencias, posee un "sabor todo especial".

Palabras-clave: Memoria; cultura; identidad; gastronomía; Brasília.

Abstract: The present article aims to outline the gastronomic scenario of the city of Brasilia based on the narrative of one of the pioneers of the local gastronomy market, Francisco Ansiliero. This is the owner of the Dom Francisco network, whose business in the food business is a reference and is part of the local and national gastronomic itinerary. Through his account and supported in other literatures it was possible to arrive at some considerations about the current scene of the Brazilian gastronomy, which due to its multiplicity of influences, has a "special flavor".

Keywords: Memory; culture; identity; gastronomy; Brasília.

\section{INTRODUÇÃO}

A gastronomia é uma importante parte na construção da cultura e da imagem de um local. É por meio dela que se pode saber sobre a biodiversidade local, sobre a interação dos habitantes com o meio ambiente, sobre os saberes-fazer e as tradições locais. A gastronomia conta uma história sobre o território. Mas qual é o processo gastronômico quando uma cidade é inventada, criada, planejada e construída do zero? Essa é a pergunta feita quando se estuda o cenário gastronômico de Brasília. Como a gastronomia da capital se constituiu quando esta estava sendo erguida e quais caminhos seguiu passadas mais de seis décadas desde sua construção?

Tecnóloga em Gastronomia (IESB, 2009); Mestra em Turismo (UnB, 2019). E-mail: claudiabrumanonasser@gmail.com. ORCID 0000-003-1102-4991.

2 Tecnóloga em Gastronomia (IESB, 2009); Mestra em agronegócio (UnB, 2012); Doutora em desenvolvimento rural (UFRGS, 2017). E-mail: tainazaneti@gmail.com. ORCID 0000-0003-3514-9510. 
O interesse pela gastronomia da capital pode revelar um importante vetor para o setor turístico da cidade, uma vez que, no Brasil, este setor representa $40 \%$ do PIB do Turismo e 53\% da mão-de-obra. Segundo Montecinos (2012, p. 7), o binômio turismo/gastronomia representa um importante aporte para o turismo, como percebido no caso da Espanha, que, "no ano 2009, teve seis milhões de visitantes internacionais que mencionaram como motivo principal de deslocamento a gastronomia e os "vinhos". Segundo o mesmo autor, a gastronomia é complemento indissolúvel do turismo, tanto por ser uma necessidade biológica vital, quanto por expressar estilos de vida.

A gastronomia é entendida como uma ferramenta turística necessária para que tal atividade possa ocorrer (Beni, 2008), ao mesmo tempo que as cozinhas regionais são também um atrativo cultural local (Schluter, 2003; Fagliari, 2005). Assim, a gastronomia se mostra como um produto turístico. Segundo Barreto (1997, p. 39):

A rede gastronômica (conjunto de restaurantes, lanchonetes e similares com oferta alimentar) pode ser um equipamento turístico ou um equipamento de apoio, dependendo de sua posição no núcleo. Se é a única oferta alimentar do local, será um equipamento turístico. Se atende turistas esporadicamente, será um equipamento de apoio [...] o tipo de usuário que definirá se um equipamento é turístico ou não.

Diante deste cenário que evidencia o crescimento do interesse social pela gastronomia, bem como sua importância na constituição da identidade local, este artigo pretende, reconstituir como o circuito gastronômico de Brasília foi se desenvolvendo ao longo do tempo. Isto é, como cozinheiros, chefs, restaurantes, ingredientes, técnicas culinárias, mercados, mídia especializada e eventos foram formando o setor gastronômico de Brasília, sob o olhar do chef pioneiro Francisco Ansiliero.

Sarlo (2007) afirma que a narração da experiência está unida ao corpo e à voz, a uma presença real do sujeito na cena do passado, não há testemunho sem experiência, nem há experiência sem narração. A narração inscreve a experiência em um estado que não é a de seu acontecer, e sim a de sua lembrança; a cada vez que ela é repetida, ela volta a se atualizar. Lançou-se mão da fonte oral como forma de registro, baseado em Thompson (1992), que nos diz que o registro através da fonte oral está na base da mais antiga e da mais recente forma de fazer história. Ele expressa também que:

[...] a história oral pode dar grande contribuição para o resgate da memória nacional, mostrando-se um método bastante promissor para a realização de pesquisa em diferentes áreas. É preciso preservar a memória física e espacial, como também descobrir e valorizar a memória do homem. A memória de um pode ser a memória de muitos, possibilitando a evidência dos fatos coletivos (Thompson, 1992, p. 17).

Uma vez que existem poucas pesquisas sobre a gastronomia de Brasília e sua construção cultural alimentar, entendemos que a história oral é um meio de registro que auxilia a construção de argumentos futuros para próximas pesquisas e trabalhos nessa área, pois, como nos explica Jan Vansina (1982), especialista em tradição oral africana: "Uma sociedade oral reconhece a fala não somente como um meio de comunicação diária, mas também, como um meio de preservação da sabedoria dos ancestrais" (Vansina, 1982, p. 157).

Corroborando Vansina (1982), Freitas (2006) demonstra esse entendimento em relação à fonte oral quando diz que: "Essa tradição oral pode ser definida, de fato, como um testemunho transmitido verbalmente de uma geração para outra" (Freitas, 2006). Por isso, essa foi a metodologia usada para essa pesquisa. Ademais, foi realizada pesquisa bibliográfica sobre a temática e efetuada busca em diversas mídias e material sobre gastronomia em Brasília, com o intuito de identificar, entre os chefs locais, qual seria o mais antigo e permanecia no mercado até os dias atuais. Apurou-se que, nos estudos sobre 
gastronomia em Brasília, Francisco Ansiliero é referência e aparece como pioneiro desse setor há mais de 30 anos. A partir desse fato, optou-se por delinear o olhar sobre o cenário gastronômico de Brasília através de sua narrativa, colhida por meio de entrevista realizada no dia 10/06/2015, às 9h no Restaurante Dom Francisco da ASBAC (Associação dos Servidores do Banco Central) em Brasília. Dessa forma, realizou-se entrevista semiestruturada, degravação e, por fim, análise de conteúdo.

Filho de imigrantes italianos, Francisco nasceu no Sul do Brasil, no estado de Santa Catarina, porém, tem passagem por vários estados brasileiros, como Paraná, Mato Grosso do Sul, Rondônia e Amazonas. Durante sua trajetória de vida, seu interesse pelo ato de cozinhar o trouxe até a Capital Federal na década de 1980, quando teve início efetivamente a sua vida de cozinheiro e empreendedor. Pretende-se, por meio do seu testemunho e das manifestações de suas memórias, relatar a importância das representações adquiridas de seu grupo familiar e outros hábitos percebidos através da convivência com portugueses Trás-os-Montes em São Paulo e com índios do Amazonas, na construção da sua identidade com o alimento e a gastronomia. Busca-se apontar, ainda, a sua contribuição na construção do mercado gastronômico da Capital Federal, e sua relevância para o turismo local e nacional.

Este artigo está dividido em quatro partes, além dessa introdução. Na primeira, será mostrado sob quais intenções Brasília foi criada, sua construção e como isso influenciou a criação de seu diverso cenário gastronômico. Na segunda parte, é trazida a narrativa do chef Francisco, que conta, sob seu olhar, como a gastronomia de Brasília se desenvolveu, remetendo a seu papel e dos outros atores que o acompanharam nessa empreitada. $\mathrm{Na}$ terceira parte, é abordado como a globalização influenciou na homogeneização alimentar e como o papel de Francisco e sua gastronomia se mostram como um elemento de resistência a esse fenômeno. Por fim, são apresentadas algumas considerações finais.

\section{UM SABOR TODO ESPECIAL: A CONSTRUÇÃO DO CENÁRIO GASTRONÔMICO DE BRASÍLIA}

Brasília foi construída a partir da busca pela centralização e unificação do país, remetendo à união de todas as culturas, e foi um marco histórico que reconfigurou o Cerrado brasileiro em múltiplas dimensões, inclusive, a gastronômica. Com planos de ser construída desde 1823, por José Bonifácio, então ministro de Dom Pedro I, a capital só foi inaugurada em 21 de abril de 1960, pelo presidente à época, Juscelino Kubitscheck, com o projeto de Lúcio Costa e Oscar Niemeyer (Mirador, 1980). Apesar da ideia de trazer a capital para o interior do país ter demorado mais de um século para se concretizar, Brasília foi construída em 41 meses após assinatura de JK no projeto de lei que criava a NOVACAP e delimitava a área do Distrito Federal. Para tanto, foi necessária a vinda de migrantes de todo o país para ajudar na construção da moderna capital brasileira (Zaneti, 2015).

Segundo Ribeiro (2004), nos primeiros meses de construção, já havia cerca de 12.700 pessoas, vindas de todas as partes do Brasil, habitando o entorno de Brasília, principalmente a área do Núcleo Bandeirante, conhecida como Cidade Livre. Esse espaço não apenas concentrava os habitantes, como também o comércio, que passou a se moldar a fim de comportar todas as culturas ali encontradas. Antes mesmo de ficar pronta, Brasília já constituía sua identidade marcada pela mistura de culturas de todo o país. Essa identidade múltipla se refletiu no circuito gastronômico da capital. Para Ribeiro (2004), a gastronomia brasiliense é uma das principais fontes de manifestação da sua miscigenada cultura, que se reflete nos inúmeros e variados restaurantes internacionais e de comidas típicas regionais, como mineira, goiana, gaúcha e nordestina (Zaneti, 2015).

Além dos migrantes brasileiros que se concentraram na capital, há também imigrantes internacionais que aqui se instalaram, tanto pela presença de empresas multinacionais, quanto pela incidência de 90 embaixadas e representações diplomáticas, que dão a Brasília uma característica cosmopolita. Por este motivo, Brasília foi considerada 
pelo Guia 4 rodas (2012) como terceiro polo gastronômico do país. Uma amostra deste polo de gastronomia diversificada pode ser percebida no Guia Gastronômico Veja Comer e Beber Brasília, edição 2014, que concentra 214 restaurantes, divididos em 20 categorias, como comida Alemã, Brasileira, Contemporânea e Espanhola. Pode-se inferir, portanto, que a capital abarca uma vasta diversidade de tipos de restaurantes (Zaneti, 2015).

Além disso, nota-se que, para além da diversidade de cozinhas internacionais, há diversos chefs, representados por Alice Mesquita, Dudu Camargo, Francisco Ansiliero, Mara Alcamin, Luis Hernandez, Simon Lau, Marilde Cavaletti, Rita Medeiros, Ademir Gudrin, Lui Veronese, Leandro Nunes e Agenor Maia, que buscam, em seus restaurantes (sendo eles de cozinha contemporânea, francesa, italiana, variada, sorveteria e brasileira), utilizar produtos do Cerrado em seus preparos, como forma da promoção da cultura e da preservação do Cerrado, de explorar, (re)conhecer e se apropriar dos sabores deste bioma (Zaneti, 2012).

Nota-se, então, que a capital não tem, ainda, uma gastronomia típica, mas sim uma gastronomia própria construída por identidades múltiplas que aqui se instalaram, vindas de todas as partes do Brasil e do mundo. Fragmenta, assim, sua cultura em diversos aspectos, não compondo um só prato típico ou um só sotaque, mas incorporando os diversos aspectos culturais que nela se encontram. O que se pode inferir é que, talvez, seja essa multiplicidade de culturas que torne Brasília lugar onde o típico seja encontrar de tudo um pouco, conferindo a ela, como nas palavras de Tom Jobim, um sabor todo especial (Zaneti, 2012).

E importante ressaltar a ínfima quantidade de pesquisas e materiais que contemplam a diversidade de estabelecimentos de alimentos e bebidas no Distrito Federal, em suas diferentes regiões administrativas. Tendo em vista que Brasília é considerada um polo gastronômico (Guia 4 Rodas, 2012), e que a capital tem cinco cursos técnicos e tecnólogos em gastronomia, nota-se que este é um campo de estudo fértil, porém ainda pouco explorado. Não há qualquer estudo de mapeamento e/ou de análise do perfil gastronômico de Brasília. São poucos os guias gastronômicos e materiais informativos que mostram a identidade gastronômica da capital e aqueles que existem têm enfoque apenas no Plano Piloto, sem abordar questões históricas e socioculturais da formação gastronômica da cidade e suas diferentes regiões administrativas (RAs).

\section{A GASTRONOMIA BRASILIENSE SOB O OLHAR (OU O DOM) DE FRANCISCO}

Sabemos que o alimento é uma das muitas formas de preservar as memórias, a história, a trajetória e a cultura de um povo. Em função disso, o trabalho em torno dos hábitos e das práticas alimentares de um grupo social nos permite compreender aspectos importantes quanto à sua cultura. Entre outros fatores, compreendemos que a alimentação é determinada também pelas condições sociais, geográficas e econômicas, está enraizada na cultura, carregada de significações históricas que são construídas ao longo do tempo. No entanto, ela é dinâmica e se transforma de acordo com as mudanças das próprias sociedades, e é esse movimento, essa capacidade de mudança que garante a sua continuidade enquanto identidade cultural. Todavia, a reflexão proposta com base na história oral aqui registrada se reflete no seguinte viés: o fetichismo e a massificação que estão sendo criados em torno da alimentação não são extremamente exagerados? Não estaria o alimento se tornando um produto mais turístico do que cultural? Que relação cultural com o alimento, que memórias e quais identidades as crianças de hoje terão na sua vida adulta em função do fenômeno da globalização?

No caso em estudo, o narrador é Francisco Ansiliero, nascido no dia 10 de setembro de 1939, em Videira, Santa Catarina, filho de imigrantes italianos de origem Celta, que migraram para Treviso, região do Vêneto, situada no norte da Itália, mais precisamente na província de Castelo Franco. A saga da família Ansiliero completou 103 anos de Brasil em 2015. A partir da evocação de suas memórias individuais e coletivas, ele vai reconstituir toda a sua identidade cultural com o alimento e a relação que foi criada com 
a gastronomia em Brasília. Em sua fala, ele rememora a sua origem através das lembranças, hábitos e tradições de família. O mito de origem, está presente quando ele diz:

[...] Eu sou cidadão Castelo Franco, Vêneto, nasci no Brasil, mas a gente conservou cidadania italiana, meu avô fez questão, minhas filhas são italianas tal, se tiverem filhos podem registrar na embaixada como italianos $[\ldots]$.

A sua relação com o alimento é reportada desde sua infância por volta dos 12 anos, quando ele temperou o primeiro frango, porém, desde os oito anos, o pai já tinha o hábito de colocar um pedaço de carne no espeto para cada um dos irmãos salgar e assar sua própria carne, meninos e meninas. Assim, diferentes hábitos foram se desenvolvendo a partir de práticas e relações sociais que se estabeleciam conforme as tradições e crenças familiares. Ele recorda:

[...] eu como cozinheiro não sou um cara que aprendeu pratos, eu vivi os pratos, da minha infância sulista; a carne, a picanha, a carne na brasa, que domingo que não tivesse churrasco parecia que não era domingo, certo? [...] meu pai dizia; que quando não tivesse salada não tinha nada pra comer $[\ldots]$.

Uma das propriedades da memória é a capacidade de conservar informações passadas, ou que ela representa como passadas, e atualizar essas informações através da releitura desses vestígios. A evocação dessa memória, a celebração através de um acontecimento memorável, segundo Le Goff (1990), é uma das formas da memória coletiva. São lembranças vividas pelo indivíduo e que não pertencem só a ele e, neste caso, fazem parte das memórias coletivas de seu grupo familiar. Esse tipo de memória quase sempre gira em torno de lembranças do cotidiano de um grupo, fundamentando a própria identidade do grupo em que o sujeito está inserido. Nessa perspectiva, compreende-se que os hábitos alimentares estão vinculados à memória.

A primeira formação de Francisco é como Professor Universitário, Mestre em Psicologia Educacional. Durante este período como Professor, ele viveu muitas experiências relacionadas à alimentação e à cultura de povos distintos, como:

[...] convivi com os portugueses Trás-os-Montes em São Paulo, quem mais usa bacalhau é transmontano, que tá longe do mar, [...] convivi muito com os transmontanos na minha juventude e peguei o gosto pelo bacalhau, sobretudo o bacalhau assado na brasa, e da minha saga amazônica eu achei o tambaqui o melhor peixe,[...] mas era grelhado, assado, então a tradição maior no convívio que eu tive com os índios, tudo isso, era sempre assado o peixe[...].

Nos estudos de Geertz (1989), o autor aponta que a cultura está na sociedade onde vive o indivíduo. Ele não vê a cultura como uma ciência experimental, e sim como uma ciência interpretativa, cheia de significados. É nessa teia de signos e significados representados pelas heranças e tradições familiares, bem como pela convivência com sujeitos de outras culturas que Francisco foi delineando seu gosto e prazer em trabalhar os alimentos e suas infinitas formas de preparo.

Quis o destino que, entre tantas idas e vindas pelo Brasil, Francisco se aportasse com a família, esposa e duas filhas, nos anos 1980, em Brasília, ainda no ofício de professor. Entretanto, ainda praticando ações como cozinheiro, mesmo que no âmbito familiar e com amigos, uma vez que a sua relação com a culinária sempre foi muito forte em função da sua descendência italiana, que é um povo de fortes tradições na cultura gastronômica. Sua vida de restauranteiro teve início efetivamente em 1988 quando, depois de uma pesquisa de mercado, ele identificou a carência de um empreendimento que 
atendesse aos anseios de um público que até então não tinha visto algo que viesse para ficar definitivamente, tudo em Brasília era passageiro, temporário.

[...] a maioria abria restaurante pra ganhar dinheiro, pra sei lá, diziam que era lavanderia, eram um bando de coisas que diziam, e tinham uma função de trabalhar de março a novembro. Dezembro fechavam, julho também muitos fechavam, eles tinham bem o caráter do ciclo político de Brasília [...] e eu entrei exatamente com essa filosofia, [...] fazer um trabalho sério, quando eu abri já tomei essa decisão [...] a gente entrou pra dar certo [...] quando eu entrei tava começando os restauranteiros de visão profissional, de fazer de fato um negócio, como eu, um negócio de família ou um negócio para efetivamente ter lucro, [...] tem uma outra coisa que sempre chamou a atenção dos brasilienses. São Paulo sempre imantou os brasilienses, certo? Brasília sempre se moveu ao redor da gastronomia paulista, sempre se deslumbram com as coisas que acontecem em São Paulo, [...] era assim, ainda hoje é assim [...].

Portanto, nessa época, Brasília contava, de acordo com as informações de Francisco, além de churrascarias, praticamente três Restaurantes de expressão; um em Taguatinga, que servia peixe assado vindo de Manaus; outro na Galeria do Ouvidor, que servia um belíssimo bacalhau; e alguns aventureiros que serviam picanha, entretanto sem muito conhecimento de cortes e preparo. Porém, eles foram dizimados por motivos vários e foi neste momento que Francisco identificou, como ele próprio diz, a oportunidade de entrar no mercado.

[...] havia então os órfãos do tambaqui, os órfãos do bacalhau e vamos dizer assim os órfãos da picanha, então a sugestão foi eu fazer o restaurante em cima desses 3 pratos que contavam a minha história [...] Não foram coisas que eu fui aprender pra fazer, etc., eu vivi essas experiências por isso eu digo, o meu cardápio não é um cardápio estudado tal, pesquisado não, é um cardápio que eu vivi, certo?

Ele acrescenta que, quando abriu o restaurante com essas três propostas, introduziu uma tradição de família, a salada, pois uma das coisas que aprendeu com seu pai foi fazer horta e comer salada todos os dias. Brasília não tinha saladas. Salada se traduzia em batata, cebola e tomates. Foi quando também começou a sua relação com o Ceasa, mais precisamente com a "Pedra" do Ceasa. Ele diz:

[...] hortelã e alecrim eram as duas coisas que tinha, e coentro, mas o resto era um deserto, então aí tinha que pedir 72 horas antes pra ter o produto, [...]. A Pedra do Ceasa foi fantástica pra despertar a noção da qualidade, organização, do senso de embalagem, porque hoje você viaja pelo mundo a fora, visita grandes feiras gastronômicas ou visita grandes mercados, você vem pra Brasília e vai na Pedra do Ceasa, você fica impressionado com a qualidade dos produtos, a variedade, a boa exposição dos produtos pra venda e os preços também [...] a gente fazia as compras no escuro, antes de acender as luzes do Ceasa que era às 5 da manhã [...] eu fui martelando muito que não adiantava ele trazer um maço enorme de tomilho, um maço enorme de alecrim, tinha que trazer um macinho pro cara usar, quê que ele ia fazer dum maço daquele que as vezes era mais caro que o peixe? Falei, era mais caro o molho do que o peixe [...] fui fazendo a cabeça dos produtores do Ceasa, [...] hoje você compra por $\mathrm{R} \$ 2,00$ um macinho de sálvia, um macinho de coentro [...].

Neste momento de sua fala, percebe-se a sua preocupação em diversificar a oferta de hortaliças no mercado de Brasília, compartilhando com os produtores uma melhor forma de se comercializar esses produtos, o que geraria maior demanda e menor custo. A sua 
filosofia é um diferencial no mercado gastronômico de Brasília, uma vez que, lá nos anos 80, ele já demonstrava engajamento em relação à sustentabilidade e ao respeito à cadeia alimentar. Interessante perceber que o imaginário constituído pelos sujeitos em relação à existência do Restaurante é dado pela associação dos tempos, representado pelos símbolos do peixe, do bacalhau e da picanha, esta simbologia reporta a um pertencimento.

[...] tem gente que jura que o Restaurante tem 40 anos, porque eles associam os tempos, do peixe em Taguatinga, do Bacalhau na Galeria do Ouvidor, da picanha que a tempos eles estavam esperando. A sensação que eles têm é que o Francisco tem mais de 40 anos e na verdade vai fazer 27 em julho de 2015 [...].

Para Le Goff (1990), este imaginário está no campo das representações como uma tradução não reprodutora, e sim criadora, poética, ela é parte da representação, que é intelectual. A tradição estabelecida em torno desses três elementos da culinária por ele oferecida se tornam uma questão complicada no dia a dia. Por várias vezes, ele já tentou introduzir outros pratos em função da sazonalidade, porém o bacalhau, a picanha e o tambaqui continuam sendo a marca registrada do seu negócio enquanto atrativo do turismo gastronômico de Brasília.

[...] porque de dia, não adianta nem eu pensar, a turma vem aqui comer 1 . Bacalhau, 2. Picanha e 3. Tambaqui, não me meto a dar palpite que o cara responde meio com casca grossa. Uma vez tava um pessoal ai; "nós viemos de São Paulo pra comer o bacalhau na brasa, a gente não quer saber o que você fez mais", tá bom, come bacalhau na brasa, fazer o que? Falaram tanto pra ele desse bacalhau [...] ele disse assim; "se eu viesse aqui e não comesse eu ia ficar frustrado" [...].

Francisco inovou e arrojou a gastronomia de Brasília ao inaugurar o seu restaurante com adega climatizada, câmara fria para lixo, e outros.

[...] então, eu fiz a primeira adega climatizada, fiz a primeira câmera de lixo de Brasília de restaurante, fui abrindo com tudo isso já, primeira adega climatizada, eu era doido, primeira adega que fiz cabia 1500 garrafas de vinho, cheguei a ter 30 e poucas mil [...] Brasília não tinha vinhos, não tinha taças e não tinha vinhos climatizados, foi outra briga que eu enfrentei, e o preço era maluco, eles iam na prateleira do supermercado, pegavam um vinho e multiplicavam por 3, 4 e pronto, ai o lugar que eu sofri mais pressão, [...] era difícil naquele tempo, tinha que trazer vinho de São Paulo [...].

Todos esses diferenciais foram importantes na sua permanência e solidificação no mercado gastronômico e turístico de Brasília.

\section{A REVERBERAÇÃO DA GLOBALIZAÇÃO E O PAPEL DA GASTRONOMIA COMO MECANISMO DE RESGATE DE TRADIÇÕES E CULTURA ALIMENTAR}

A arte de combinar os ingredientes com os temperos é uma alquimia que, aliada aos rituais de preparação e serviços da alimentação, fazem parte do universo da herança cultural de grupos sociais. As escolhas e os rituais relativos à alimentação são socialmente estabelecidos e se relacionam diretamente à posição que determinadas sociedades ou grupos sociais ocupam. A comida opera como um elemento de pertença. Quando Francisco se refere ao alimento como uma forma de aproximar e unir as pessoas, ele lembra um momento de crise por que passava a classe média de Brasília.

[...] quando cheguei aqui, a classe média tinha perdido a mesa e estava perdendo os filhos, o que significa isso? Não tinha mais as refeições em família e os filhos não tinham mais um ponto de referência pra encontrar 
com ninguém, aí era um desespero nessa cidade há 30 anos atrás de, no fim de semana procurar filho em necrotério, foi coisa séria, você não faz ideia do que foi aquela época, uma verdadeira loucura, 4,5 jovens morrendo de uma vez só, era a coisa mais simples, realmente uma coisa terrível, quer dizer a modernização perdeu a mesa e em seguida perdeu a família, terrível, os filhos não tem mais referenciais, porque esse povo que tá ai agora, qual é a referência que eles têm de comida? Nenhuma, é o que? McDonald's?

Elias (1994) argumenta que, com o desenvolvimento do "processo civilizador", os hábitos alimentares foram sendo sofisticados, quanto maior for o "estágio de civilização", mais o alimento vai se distanciar de suas formas naturais. Produtos como a mandioca, o arroz e o feijão, que sempre foram a base da alimentação da maioria da população, perdem cada vez mais espaço para os produtos industrializados e com maior valor agregado.

Percebe-se, então, que a globalização é um fenômeno que gera modificações nos hábitos alimentares do indivíduo, provocando profundas transformações na sua cultura alimentar. Ela impõe novas formas de consumo, afetando o paladar, criando novos padrões e hábitos alimentares, estimulando o consumo de alimentos industrializados e artificiais em detrimento de produtos regionais e tradicionais. Dessa forma, a pós-modernidade, embalada pela globalização, dizima com rituais que acompanham 0 ato de alimentar. A refeição de afeto que antes permeava a reunião nas trocas familiares e entre amigos, hoje cede lugar aos Fast Food. Na contemporaneidade, o ato de comer, muitas vezes, deixa de ser algo prazeroso, passando a ser algo ligado apenas às necessidades biológicas do sujeito, diferentemente das necessidades culturais, de prazer e de estreitamento de relações que aconteciam no passado.

Conhece-se a cozinha brasileira como uma mescla de memórias populares e regionais, e o deslocamento de grupos de uma região à outra do país introduziu na cozinha essas relações. Ainda segundo Le Goff (1990), esse tipo de memória é um elemento essencial do que se costuma chamar identidade, individual ou coletiva, cuja busca é uma das atividades fundamentais dos indivíduos e das sociedades.

Sabe-se que a cozinha brasileira é dividida em cozinhas regionais. Essa regionalidade faz parte da construção de uma identidade coletiva, pois está diretamente ligada ao cotidiano de determinados grupos e regiões. Na perspectiva de Francisco, as identidades regionais estão bem representadas quando ele diz:

[...] culinária tradicional significa história, vida, engajamento [...] veja o contexto em que eu vi e que eu nasci, foi um contexto que, para min a culinária tradicional é basicamente os produtos, a minha cozinha é uma cozinha de produtos, a minha história é uma história com produtos da terra, da região onde eu vivi, tá bem? [...] pesquisar Pirenópolis pra fazer pratos, isso ai pra min não faz sentido, quem viveu em Pirenópolis é que tem a história de Pirenópolis e tem no sangue, nas veias, os produtos que estão ali, que modelou o corpo deles, a mente deles, é isso. O homem representa aquilo que ele come, muito mais do que ele pensa, ele é a imagem, o retrato do que ele come, então pra min, a culinária é, como se diz, aquele berço onde você vive e as coisas acontecem, ai tem os produtos, você vai trabalhando, agregando coisas novas daquela região que vão acontecendo, então, eu não posso fazer uma culinária de cerrado, sem desconhecer ou desconhecendo meu passado com a ligação com os produtos, com os produtos que eu sei manipular, que eu sei comer, que eu gosto de comer, tá certo? A comida, eu sempre digo, tem que dar prazer quando se come e bem-estar depois, se você não sentir prazer quando você come, ela é falha, $o$ ato de comer deve ser um ato prazeroso para as pessoas. O que é mais prazeroso pra você do que sua infância? Você já parou pra pensar quando tá com fome? Quê que você lembra? [...] eu lembro do churrasco, eu lembro de macarrão com frango, aquele macarrão que a gente fazia em casa [...] isso que me dá prazer, ir buscar o frango [...]. 
Nessa perspectiva, percebemos que as tradições na cultura alimentar estão no saber do povo, ligadas à terra e à exploração dos produtos da região e das estações, e estão sempre sendo renovadas e ressignificadas. Assim, compreendemos que a culinária possui significados e simbolismos diversos nas diferentes formas de cultura, e a comida, portanto, transcende seu significado para além do ato de satisfazer biologicamente. Existem verdadeiros rituais construídos em torno da alimentação de um povo. Muitas das vezes, filhos de imigrantes nunca foram fisicamente ao país de origem de seus pais, porém, culturalmente, eles o conhecem devido à forte presença de hábitos, costumes e tradições que lhes foram apresentadas no convívio familiar. Desse modo, através da cultura alimentar, costumes e hábitos são usados para que pessoas compartilhem suas tradições. Consequentemente, podemos dizer que, através da gastronomia ou do uso do alimento, preservamos as memórias, histórias e trajetórias de um povo.

Percebemos que as novas tendências nos hábitos alimentares geradas pelas migrações humanas em torno do globo terrestre podem levar tanto à homogeneização quanto à diferenciação da alimentação. Um exemplo disso é a ascensão da gastronomia, com destaque para a comida que representa culturas tradicionais, como comida chinesa, mexicana, peruana, árabe, tailandesa, etc. Observa-se que é possível comer sushi até em churrascarias, e essas adaptações entre a culinária estrangeira e a culinária receptora afetam não só os produtos ou os sabores, como também as estruturas profundas da culinária de origem. Ao mesmo tempo, na visão de Stuart Hall (2003), a cultura se encontra em um estágio, atualmente, em que a produção e a distribuição de seus produtos adquiriram independência em relação às comunidades. A maioria dos padrões culturais viajam o mundo, a tecnologia permite que eles ultrapassem fronteiras. Isso não significa que ela perdeu sua identidade como cultura (Hall, 2003).

Essas transformações que acontecem na atualidade refletem as consequências do Multiculturalismo, em que os sistemas de significação e representação cultural se multiplicam, provocando mudanças rápidas, constantes e permanentes nas identidades culturais. Enquanto, nas sociedades tradicionais, Anthony Giddens (1990) argumenta:

O passado é venerado e os símbolos são valorizados porque contém e perpetuam experiência de gerações. A tradição é um meio de lidar com o tempo e o espaço, inserindo qualquer atividade ou experiência particular na continuidade do passado, presente e futuro, os quais por sua vez, são estruturados por práticas sociais recorrentes (Giddens, 1990, p. 37-38).

Como diz Le Goff (1990), a memória é o antídoto do esquecimento, a fonte da memória é uma fonte de imortalidade. Esta definição de Le Goff (1990) está relacionada com a reflexão de Francisco quando ele demonstra sua preocupação com o Cerrado brasileiro enquanto detentor de uma memória de produtos que lá ainda existem.

[...] uma coisa que me dá assim um certo pesar, a gente tá vendo o Cerrado se esvaindo sem nem sequer tê-lo degustado, cheirado, comido, participado dele, né? [...] o tempo vai passando, os produtos vão se indo e você não vai ter nem a memória das coisas [...] eu acho que é um momento muito importante e também com essa, um pouco de sentimento de Brasília, de brasilidade, não brasilidade de Brasil, brasilidade de Brasília, um pouco de olhar com mais amor, mais carinho para o local onde estão morando, tá começando um momento de valorizar as coisas da região [...] antigamente digamos assim, era imitar, queriam achar as coisas que achavam sobretudo em São Paulo e ai os cozinheiros foram muito atrás disso, e hoje não, hoje a turma tá sentindo espaço, tá tendo clientes pra fazer inovações, descobrir caminhos, descobrir aromas, sabores que estão no Cerrado que é extremamente rico, né? 
Compreendemos que o processo de globalização invade os costumes alimentares da humanidade. Ao mesmo tempo, observamos movimentos de retorno à alimentação de origem, em que ocorre um resgate dos alimentos e dos hábitos alimentares voltados à sazonalidade, aos orgânicos e até à própria preocupação em manter práticas de alimentação mais saudáveis. Estas buscas acabam por criar um movimento de resistência à homogeneidade alimentar provocada pela globalização. O Comfort Food, Slow Food e outros são exemplos de movimentos que se opõem à tendência de padronização do alimento no mundo. Podemos dizer que eles vão na direção contrária ao Fast Food em termos de conceito e contribuem para este novo conceito de gastronomia, que conjuga o prazer e a alimentação com consciência ambiental e responsabilidade social. A culinária de Francisco se encaixa neste perfil de movimento, como se observa a seguir.

[...] Eles que me procuraram, foram comer no meu restaurante e acharam meu perfil de Slow Food pelas coisas que eu trabalhava, os produtos da região que eu manipulava, me entusiasmei, participei várias vezes, depois ficou muito confuso [...] eu continuo trabalhando do meu jeito, eu não mudei porque entrei no Slow Food, e também não vou fazer besteira porque não estou no Slow Food, vou continuar meu estilo de trabalho [...].

Ele encerra sua narrativa dizendo:

[...] como eu digo, uma das grandes verdades de Brasília é a Pedra do Ceasa, a Pedra do Ceasa (ele repete). Acabou com muitos sonhos e criou muitas realidades, a Pedra do Ceasa, lá, é ali, é ou não é, ou você tem qualidade e fica, ou você vai embora, hoje tem os orgânicos, tudo ajuda mas, efetivamente a Pedra que é o grande cadinho, que é onde se burilam os ouros, o cristal onde se burilam os ouros é a Pedra, separa o que é ouro e o que é escoria $[\ldots]$.

Assim, podemos dizer que a trajetória de vida e trabalho de Francisco, enquanto cozinheiro, são a imagem de um sujeito detentor de memórias, histórias e representações, sejam elas de cultura italiana, portuguesa e brasileira. São um exemplo do multiculturalismo da pós-modernidade, que, com sua filosofia, agrega ao mercado gastronômico e turístico de Brasília relevantes valores.

\section{CONSIDERAÇÕES FINAIS}

Existem muitas maneiras de conhecer a alma de um povo, uma delas, sem dúvida, é a arte da gastronomia. A arte de cozinhar não se resume a uma simples mistura de ingredientes, eles precisam ser combinados entre si de forma a produzir um resultado final que surpreenda os comensais. Dentro deste contexto, 0 ato de comer não se relaciona apenas ao sentido de saciar a fome, ele é carregado de simbolismos, remete à fraternidade, à solidariedade, ao companheirismo e tem que gerar prazer. Apesar de a comida ser um aspecto cultural relevante para a compreensão de diferentes relações sociais, ela tem se modificado ao longo dos anos, com as novas tecnologias, com as relações de trabalho, os estilos de vida, que fazem com que os indivíduos tenham novas formas de se relacionar socialmente e essa capacidade de mudança, esse movimento, é que garante a sua continuidade enquanto identidade cultural.

Desse modo, ao pesquisar o cenário gastronômico de Brasília sob a lente da história e sob o olhar de Francisco, percebemos uma cidade com marcantes diferenças na cultura alimentar em função da constituição de múltiplas identidades dos seus habitantes. É interessante perceber que a cena gastronômica de Brasília reflete a história da sua construção e localização, que, ao objetivar a centralização e unificação do país aproximando e ligando as cinco regiões entre si -, trouxeram, para a capital, diversidade de práticas e hábitos alimentares que dessa maneira constituem a identidade alimentar local. 
Essa pluralidade de influências, acrescida da rica diversidade dos produtos alimentares encontrados no bioma cerrado, constituem uma ferramenta que, bem trabalhada e explorada, pode, cada vez mais, contribuir para o turismo, o reconhecimento e a valorização de uma gastronomia com um sabor todo típico da capital federal.

Nessa perspectiva, abordar a cultura sem levar em conta a identidade, a memória e a história é quase impossível, pois o passado, a herança, a transmissão de valores, ideias e conhecimentos estarão sempre presentes entre os povos. Consideramos, desse modo, que o elemento de união entre o que existiu e o que está por ser construído - essa ligação entre o passado e o presente - é o que pode contribuir para a manutenção do equilíbrio entre os efeitos da globalização e a cultura alimentar tradicional. São essas memórias coletivas de povos e regiões distintas que, ao serem transmitidas entre gerações através dos signos e significados, fazem com que as tradições e hábitos alimentares se perpetuem.

Sabemos da relevância do segmento Gastronomia dentro do Turismo, porém, na sociedade pós-moderna, ela está sendo tratada mais como um produto turístico do que efetivamente cultural. Nunca se viu tanta informação sobre alimentação, seja em revistas, livros, jornais, para não dizer da massificação dos programas de TV de todas as naturezas, concursos, disputas, além de uma infinidade de cursos superiores para a formação de cozinheiros, que hoje tem a até a denominação "chef" de cozinha. Todo esse fetiche que está sendo criado em torno da culinária implica em um cuidado para que, em meio a este boom que vive o setor gastronômico, a cultura alimentar dos povos não seja negligenciada ou afetada. Trabalhar com o resgate de hábitos alimentares tradicionais é uma forma de resistir culturalmente à homogeneidade que está sendo imposta ao mercado da alimentação. Toda cozinha tem a marca do passado, da história, da sociedade, do povo e da nação à qual pertence. Cozinhar é uma ação cultural que nos liga sempre ao que fomos, somos, seremos e, também, com o que produzimos, cremos, projetamos e sonhamos (Soares Leal, 2008).

Acreditamos que é através de trabalhos como o de Francisco, que vê o alimento não somente como uma fonte geradora de capital, mas também com o papel de ressignificar a cultura de um povo, valorizar a comunidade onde se vive, trazer crescimento e desenvolvimento, que se encontram possibilidades de resistência e sobrevivência ao cenário global. Ele é um sujeito detentor de memórias, histórias, tradições e cultura, que foram adquiridas através das relações sociais que desenvolveu durante sua trajetória de vida e contribuem para a resistência e a manutenção de hábitos e tradições alimentares no mercado gastronômico de Brasília.

Como nos ensina Savarin (1995), somos aquilo que comemos, tanto fisiologicamente, quanto culturalmente. Portanto, é preciso que exista uma boa relação entre formas e hábitos de alimentação, e a construção do homem enquanto sujeito integrado a espaços e sistemas sociais culturalmente determinados. Concluímos, com uma das condições da teoria cultural de Clifford Geertz (1989) que diz que: não tem como antecipá-la ou prever o que vai acontecer a ela, ela simplesmente tem que sobreviver aos fenômenos sociais que acaso ocorram no futuro (Geertz, 1989). O importante é questionar a sua importância e o que está sendo transmitido através dela.

\section{REFERÊNCIAS}

Barbosa, L. (2009) Tendências da alimentação contemporânea. In: Pinto, M. L.; Pacheco, J. K. (Org.). Juventude, consumo e educação (2. ed). Porto Alegre: ESPM, p. 15-64.

Barreto, M. (1997) Manual de iniciação ao estudo do turismo (3. ed). Campinas: Papirus.

Elias, N. (1994) A sociedade dos indivíduos. Rio de Janeiro: Jorge Zahar.

Elias, N. (1994) O processo civilizador. Rio de Janeiro: Jorge Zahar. 


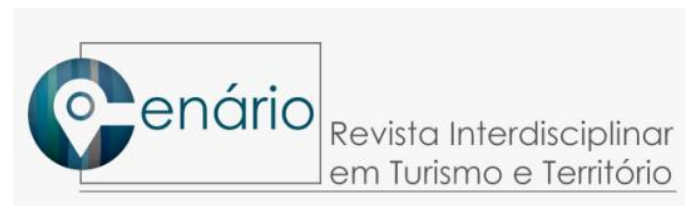

Freitas, S. M. de. (2006) História Oral: Possibilidades e procedimentos. São Paulo: Associação Editorial Humanitas.

Geertz, C. (1989) A interpretação das culturas. Rio de Janeiro: LTC S.A.

Giddens, A. (1990) Modernidade e Identidade. Rio de Janeiro: Jorge Zahar.

Hall, S. (2003) A identidade Cultural na Pós-modernidade. Rio de Janeiro: DP\&A.

Le Goff, J. (1990) História e memória. Campinas: Editora da Unicamp.

Mirador (1980) Enciclopédia. São Paulo: Ed. Enciclopédia Britânica do Brasil Publicações Ltda.

Montecinos, A. (2012) A importância do planejamento gastronômico para o turismo. Turismo em Pauta / Confederação Nacional do Comércio de Bens, Serviços e Turismo - N. 10 - Rio de Janeiro:

Oliveira, B. R. (2013) A gastronomia como produto turístico: uma análise do potencial gastronômico da cidade de Natal/RN. p. 137. Monografia, Universidade Federal do Rio Grande do Norte, Natal, Brasil.

Ribeiro, C. G. C. (2004) Aspectos Culturais Contidos na Gastronomia Brasiliense como Atrativo Turístico. Trabalho de conclusão de Curso, IESB, Brasília, Brasil.

Savarin, B. (1995) A fisiologia do gosto. São Paulo: Companhia das Letras.

Sarlo, B. (2007) Tempo passado Cultura da memória e guinada subjetiva, São Paulo: Cia das Letras.

Soares Leal, M. L. (2008) DNA história da gastronomia/Maria Leonor de Macedo Soares Leal. Rio de Janeiro: Senac Nacional.

Thompson, Paul. A voz do passado. São Paulo: Paz e Terra, 1992.

Vansina, J. A tradição oral e sua metodologia. In: História geral da África. São Paulo: Ática; Paris: Unesco, 1982, v. 1 - Metodologia e pré-história da África.

Schluter, R. G. (2003) Gastronomia e turismo. São Paulo: Aleph.

Zaneti, T. B. (2012) Das panelas das nossas avós aos restaurantes de alta gastronomia: os processos sociais de valorização de produtos agroalimentares tradicionais. Dissertação de Mestrado, Universidade de Brasília, Brasília, Brasil.

Recebido em:30/06/2018 - Aprovado em:28/08/2019 